\title{
A novel, automated method for measuring mitral valve annular velocity from standard cine TrueFISP data - a feasibility study
}

\author{
Peter J Weale ${ }^{1 *}$, Christoph Guetter ${ }^{2}$, Jeremy D Collins ${ }^{3}$, Marie Wasielewski ${ }^{3}$, Neil Chatterjee ${ }^{4}$, Marie-Pierre Jolly ${ }^{2}$, \\ Hui Xue ${ }^{2}$, Xiaoguang Lu², Jens Guehring ${ }^{2}$, Sven Zuehlsdorff', James Carr ${ }^{3}$
}

From 2011 SCMR/Euro CMR Joint Scientific Sessions

Nice, France. 3-6 February 2011

\section{Introduction}

A novel method for determining a correlate of Tissue Doppler Imaging (TDI) parameters from cine TrueFisp data. Using the velocity of automatically identified and tracked landmarks,time/velocity data and hence s', e' and a' can be derived.

\section{Purpose}

To validate mitral valve annular velocities extracted in an automated fashion using an established algorithm for database guided landmark detection and temporal propagation based on inverse consistent non-rigid registration [1] in a normal population.

To correlate the derived early diastolic myocardial peak-velocity measurements (e prime or e') against phase contrast methods and to evaluate correlation with age.

\section{Methods}

A cohort of 12 healthy volunteers (7F, 22 to 62 yrs) was recruited under an IRB approved protocol. Cine TrueFISP data was acquired in the four chamber orientation with temporal resolution of 7,10,20,30,40 and $50 \mathrm{~ms}$. with the aim of assessing the performance of the automatic tracking algorithm with increased sampling rate. e' was derived from time-velocity curves (Figure 1) extracted from the frame to frame change in position of the track points.

In a sub-cohort of 6 subjects breath-hold and free breathing phase contrast data (Venc $25 \mathrm{~cm} / \mathrm{s}$ ) was acquired in the short axis orientation at a slice position

${ }^{1}$ Siemens Healthcare USA, Chicago, IL, USA

Full list of author information is available at the end of the article where the myocardium on the apical side of the valve ring was within the slice throughout the cardiac cycle.

Lateral and septal myocardium at the intersection of the four chamber orientation was then evaluated using standard flow post-processing and e' velocities derived.

\section{Results}

For each temporal resolution, the mean e' velocity was calculated across all subjects. The results demonstrate the expected increase in detected peak e' with improving temporal resolution but at $<20 \mathrm{~ms}$ the data develops an increasing variance as illustrated in table 1 .

Using e' derived from the lateral landmark with $30 \mathrm{~ms}$ temporal resolution, a good correlation with both breath-hold and free breathing phase contrast data $(r=$ 0.80 for both) is seen.

Measured e' demonstrates an inverse correlation with subject age $(r=-0.74)$

\section{Conclusions}

This novel method of deriving mitral annular velocities is potentially a method for extracting data which may correlate with TDI.

It is simple extension of an existing algorithm which provides measurement of s' eand a' from standard imaging data. Validation against TDI is ongoing.

\section{Author details}

${ }^{1}$ Siemens Healthcare USA, Chicago, IL, USA. ${ }^{2}$ Siemens Corporate Research, Princeton, NJ, USA. ${ }^{3}$ Northwestern University, Department of Radiolgy, Chicago, IL, USA. ${ }^{4}$ Northwestern University Feinberg School of Medicine, Chicago, IL, USA.

Published: 2 February 2011

(c) 2011 Weale et al; licensee BioMed Central Ltd. This is an open access article distributed under the terms of the Creative Commons 


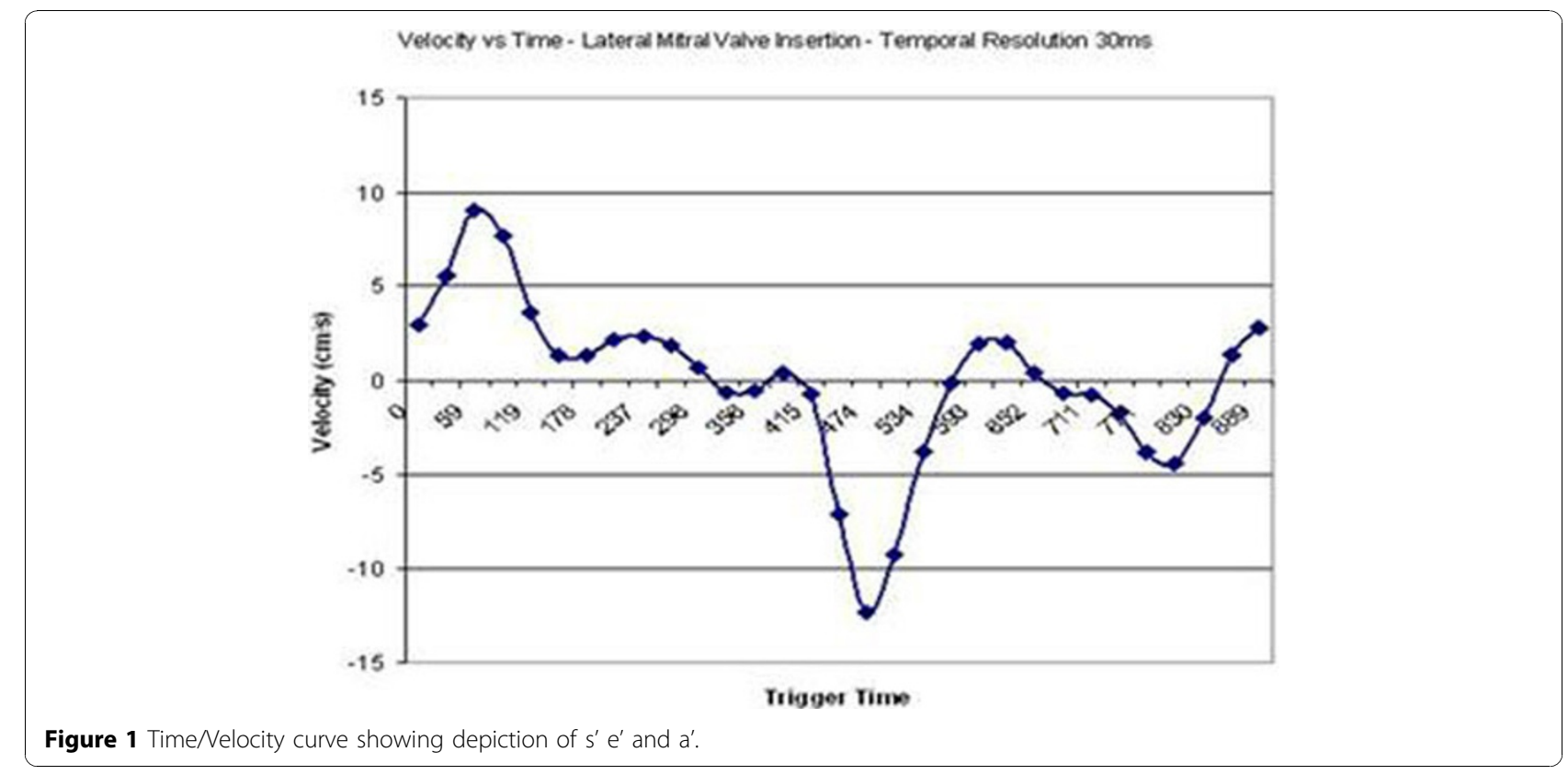

Table 1 Lateral and Septal e prime - effect of temporal resolution

\begin{tabular}{lllll}
\hline Temporal Resolution(ms) & Septal $\mathbf{~ e}^{\prime}{\mathbf{~ c m} . \mathbf{s}^{\mathbf{- 1}}}$ & Septal Standard Deviation & Lateral $\mathbf{e}^{\prime} \mathbf{~ c m} \cdot \mathbf{s}^{\mathbf{- 1}}$ & Lateral Standard Deviation \\
\hline 7 & 46.69 & 29.81 & 28.69 & 17.91 \\
10 & 26.24 & 17.83 & 18.62 & 8.02 \\
20 & 15.48 & 9 & 14.41 & 5.7 \\
30 & 10.72 & 5.81 & 10.72 & 5.81 \\
40 & 8.45 & 4.1 & 8.45 & 4.1 \\
50 & 6.37 & 2.6 & 6.37 & 2.6 \\
\hline
\end{tabular}

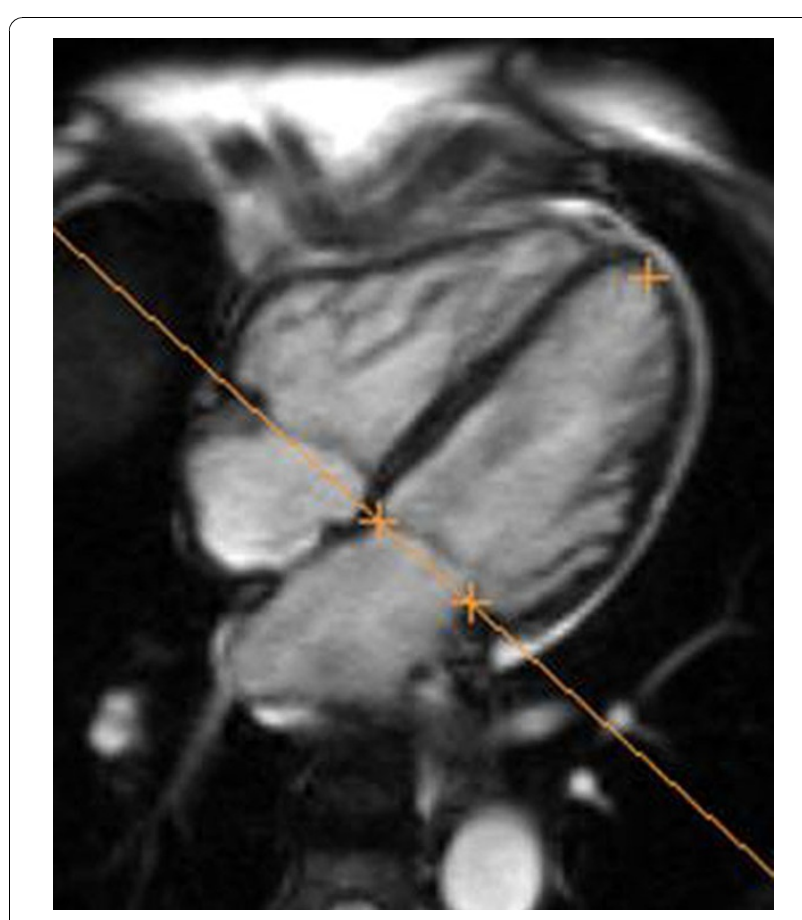

Figure 2 Automatically generated tracking points.

\section{Reference}

1. Jolly MP, Guetter C, Guehring J: "Cardiac Segmentation in MR Cine Data Using Inverse Consistent Deformable Registration". Proc.ISBI Rotterdam; 2010.

doi:10.1186/1532-429X-13-S1-048

Cite this article as: Weale et al:: A novel, automated method for measuring mitral valve annular velocity from standard cine TrueFISP data - a feasibility study. Journal of Cardiovascular Magnetic Resonance 2011 13(Suppl 1):O48.

Submit your next manuscript to BioMed Central and take full advantage of:

- Convenient online submission

- Thorough peer review

- No space constraints or color figure charges

- Immediate publication on acceptance

- Inclusion in PubMed, CAS, Scopus and Google Scholar

- Research which is freely available for redistribution 